\title{
Influence of deposition potential on structure of Zn-based nanotubes
}

\author{
Kadyrzhanov D. ${ }^{\mathrm{a}}$, Zdorovets M. ${ }^{\mathrm{a}, \mathrm{b}, \mathrm{c}}$, Kozlovskiy A. ${ }^{\mathrm{a}, \mathrm{b}}$, \\ Kenzhina I. ${ }^{\mathrm{a}, \mathrm{b}}$, Petrov A. ${ }^{\mathrm{d}}$, Kutuzau M. ${ }^{\mathrm{d}}$, Kaniukov E. ${ }^{\mathrm{d}}$, Shumskaya E. ${ }^{\mathrm{d} 1}$ \\ ${ }^{a}$ L.N. Gumilyov Eurasian National University, 2, Satpayev Str. 010008, Astana, Kazakhstan \\ ${ }^{b}$ The Institute of Nuclear Physics of Republic of Kazakhstan, 1, Ibragimov St. 050032, Astana, Kazakhstan \\ ${ }^{c}$ Ural Federal University named after the First President of Russia B.N. Yeltsin, 19, Mira St. 620002,, Yekaterinburg, Russia \\ ${ }^{d}$ SSPA "Scientific-Practical Materials Research Centre of NAS of Belarus, 19, P.Brovka Str. 220072, Minsk, Republic of Belarus
}

\begin{abstract}
The rapid growth of the market of electronic devices designed on the base of micro- and nanoelectronic components requires novel unconventional approaches for nanostructures formation. In this regard, ion-track technology, which allows forming nanostructures with a predetermined geometry is very promising. The paper demonstrates a simple and scalable approach to the creation of nanotubes based on pure zinc and its oxide. The main idea of the work is to determine the possibility of controlling of the nanotubes morphology and composition by variation of the deposition potential. In this concern, template synthesis of zinc-based nanotubes in the PET template pores is carried out at potentials in the range from 1.25 to $2 \mathrm{~V}$ and a comprehensive study of their structural and morphological features is provided.
\end{abstract}

Keywords: metallic nanotubes, Zn nanostructures, electrodeposition

\section{Introduction}

Today, significant efforts of research groups are focused on synthesizing and studying the properties of one-dimensional metallic materials such as nanotubes and nanowires [1-5]. They are perspective for application in optoelectronics, photoelectrochemistry, catalysis, medicine, etc. One of the most promising are Zn-based nanostructures, such as pure zinc and its oxide, which could be used for production of nanostructures with various shape (nanowires, nanotubes, nanoparticles) [610]. Also Zn-based nanomaterials have both metallic and semiconductor properties.

For $\mathrm{Zn}$ - and $\mathrm{ZnO}$ - based nanostructures formation are mainly used chemical vapor deposition, arc discharge method, laser evaporation and template synthesis. The most attractive is the template synthesis method due to scalability, sufficient degree of control and low cost [11-15]. The template synthesis allows obtaining nanostructures with predetermined shape and dimensions. In papers [1619] the opportunity of Zn-bazed nanowires and nanotubes by electrodeposition in pores of anodic aluminum oxide, silicon and polycarbonate templates. In our work [20] we shown the first results of peculiarities of the template synthesis method of $\mathrm{Zn}$-based nanotubes via electrochemical deposition in ion-track membranes pores. We discovered the influence of structural and composition of nanotubes on deposition potential. This fact pushed us for detailed studying of morphology and structure of Zn-based nanotubes in a wider range of deposition potential.

\footnotetext{
${ }^{*}$ Corresponding author. Tel.: +375172841147.

E-mail address: lunka7@mail.ru
} 


\section{Methods}

Track-etched polyethylene terephthalate (PET) membranes with thickness of $12 \mu \mathrm{m}$ and nominal pore density of $10^{7} \mathrm{~cm}^{-2}$ and diameter of $400 \pm 10 \mathrm{~nm}$ was used as templates [21-23]. Zn-based nanostructures were produced by template synthesis method via electrochemical deposition in pores. Electrolyte composition was: $\mathrm{ZnSO}_{4} \cdot 7 \mathrm{H}_{2} \mathrm{O}-360 \mathrm{~g} / \mathrm{l} ; \mathrm{NH}_{4} \mathrm{Cl}-30 \mathrm{~g} / \mathrm{l} ; 3 \mathrm{H}_{2} \mathrm{O} \cdot \mathrm{CH}_{3} \mathrm{COONa}-15$ $\mathrm{g} / \mathrm{l}$; ascorbic acid - $120 \mathrm{~g} / \mathrm{l}$. To provide electrodepositing gold cathode layer was made by magnetron deposition. Deposition was carried out at potentiostatic mode in the range of potentials from 1.25 to $2.0 \mathrm{~V}$ with a step of $0.25 \mathrm{~V}$. Deposition time was controlled by chronoamperometric method on Agilent 34410 system and the deposition process was discontinued in order to prevent nanotubes overgrowing of template surface [24]. Characterization of structure was made by scanning electron microscopy (SEM, Hitachi TM3030), energy dispersive analysis (EDA, Bruker XFlash MIN SVE) at an accelerating potential of $15 \mathrm{kV}$, X-ray diffraction analysis (XRD, D8 ADVANCE) using Cu $\mathrm{K}_{\alpha}$ radiation. Diffractograms were recorded in the range of angles $2 \theta 30^{\circ}-110^{\circ}$ in steps of $0.01^{\circ}$.

\section{Results and discussion}

Zn-based nanostructures obtained after removal from PET have length $12 \mu \mathrm{m}$ and diameters 400 $\mathrm{nm}$, it corresponds to the template parameters. Fig. 1a-d show typical SEM images of Zn-based nanostructures formed under different deposition conditions. The SEM images show shape as the hollow tubes (Fig. 1e).
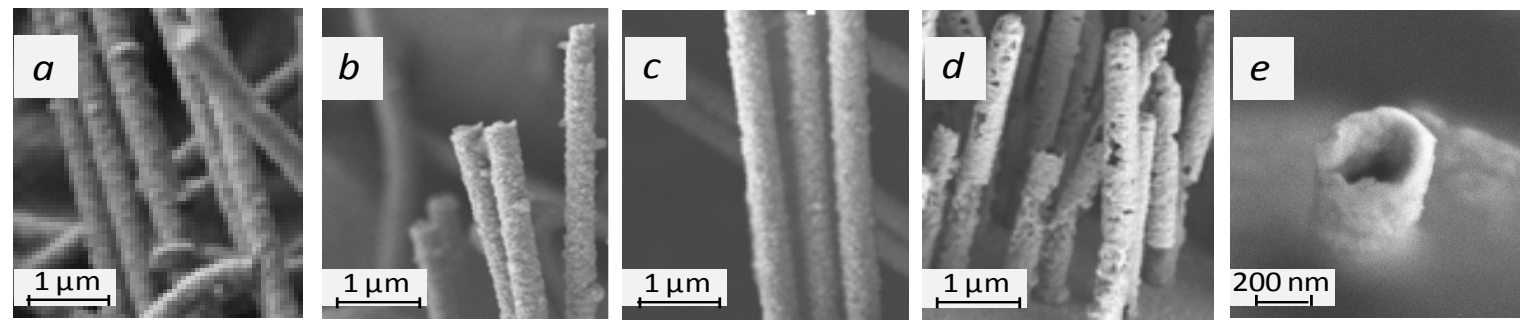

Fig. 1. SEM images of $\mathrm{Zn}$-based nanotubes synthesized at potentials:

(a) $1.25 \mathrm{~V}$; (b) $1.5 \mathrm{~V}$; (c) $1.75 \mathrm{~V}$; (d) $2.0 \mathrm{~V}$, (e) cleaved nanotube.

Nanotubes obtained at 1.25 and $1.5 \mathrm{~V}$ have surfaces with different impurities (Fig. 1a-b). At deposition potential $1.75 \mathrm{~V}$ surface of nanotubes is smooth (Fig. 1c). With an increasing of the synthesis potential up to $2.0 \mathrm{~V}$, partial destruction of nanotubes is observed (Fig. 1d). At this potential the growth process is rapid with considerable hydrogen evolution. Both facts (fast growth and hydrogen evolution) lead to the formation of nanotubes with hollow structure with thin walls [24], which are vulnerable to destruction. To determine the effect of the deposition potential on the elemental composition EDA method was used (Table 1).

Table 1. Elemental composition of Zn-based nanotubes formed at different potentials.

\begin{tabular}{cc}
\hline $\begin{array}{c}\text { Deposition } \\
\text { potential, } \mathrm{V}\end{array}$ & $\begin{array}{c}\text { Atomic } \\
\text { ratio }\end{array}$ \\
\hline 1.25 & $\mathrm{Zn}_{73} \mathrm{O}_{27}$ \\
1.50 & $\mathrm{Zn}_{86} \mathrm{O}_{14}$ \\
1.75 & $\mathrm{Zn}_{100}$ \\
2.00 & $\mathrm{Zn}_{62} \mathrm{O}_{38}$ \\
\hline
\end{tabular}


As can be seen zinc oxide phase with an atomic ratio of $\mathrm{Zn}_{73} \mathrm{O}_{27}$ occurs as a result of the deposition process at a potential of $1.25 \mathrm{~V}$. With the increasing of deposition potential to $1.5 \mathrm{~V}$, the oxide phase decrease due to the predominance of $\mathrm{Zn}$ reduction potential above the formation of $\mathrm{ZnO}$ phase. At deposition potential $1.75 \mathrm{~V}$ nanotubes consist of pure $\mathrm{Zn}$. However, at 2.0 V a sharp increase of oxygen content is observed. These results confirm the assumption of the effect of nonuniform growth of nanotubes on the oxide compounds appearance. To show the change in the crystal structure and the formation of zinc oxides phase at different synthesis potentials, an XRD analysis of nanotubes have been performed (Fig. 2).

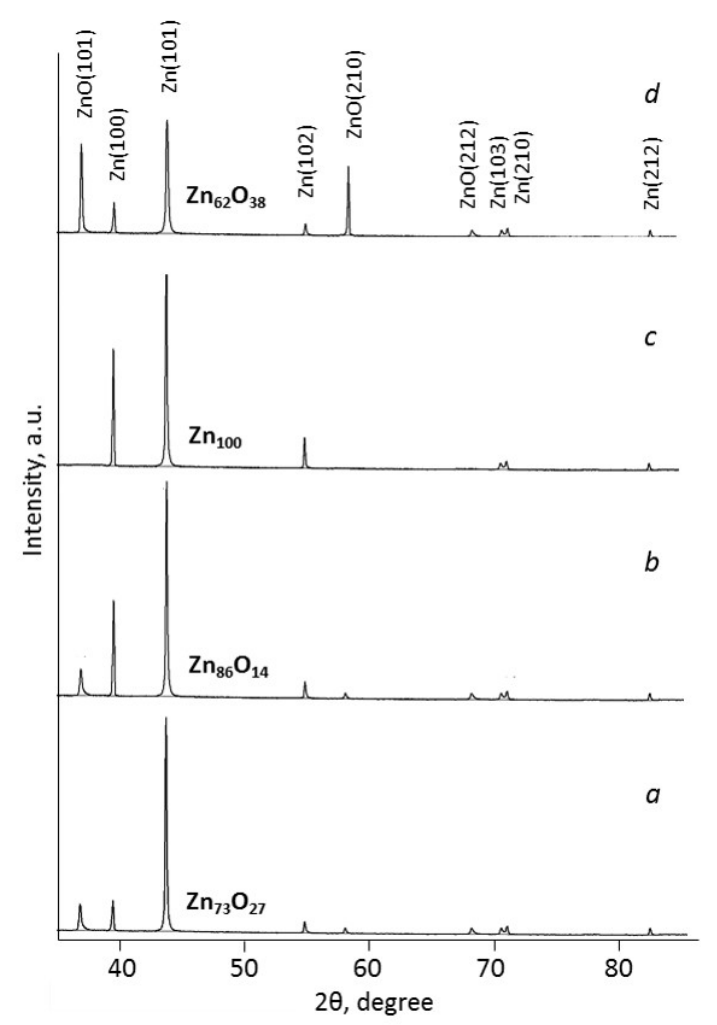

Fig. 2. X-ray diffraction patterns of Zn-based nanotubes:

(a) $1.25 \mathrm{~V}$; (b) $1.5 \mathrm{~V}$; (c) $1.75 \mathrm{~V}$; (d) $2.0 \mathrm{~V}$.

Oxide phase of $\mathrm{ZnO}$ is present in the diffractogram at 37, 58, 68 degree (Fig. $2 a, b, d$ ). With rising of the deposition potential the decreasing of intensity of the peaks of $\mathrm{ZnO}$ phase is observed. $\mathrm{ZnO}$ picks are not observed on the diffractogram at potential of $1.75 \mathrm{~V}$, which corresponds to EDA data. Thus, by electrochemical deposition it is possible to obtain nanotubes from pure zinc, without impurities of oxide phases at a potential of $1.75 \mathrm{~V}$. At the same time, at potential of $2.0 \mathrm{~V}$ there is $\mathrm{ZnO}$ peaks sharp increasing, as well as $\mathrm{Zn}$ phase peaks decreasing. Using XRD for crystal structure analysis hexagonal primitive crystal lattice is established. The lattice parameters $a$ and $c$ as well as the average crystallite sizes have been calculated (Table 2).

The lattice parameters differ from the reference one (№ 04-0831: $a=2.665 \AA, c=4.947 \AA$ ) due to the presence of a significant amount of oxygen in the structure. As can be seen from calculations the increasing of deposition potential from $1.25 \mathrm{~V}$ to $1.75 \mathrm{~V}$ leads to decrease in the average crystallite size from $41.52 \mathrm{~nm}$ to $16.22 \mathrm{~nm}$. However, the increasing of the potential up to $2.0 \mathrm{~V}$ provides dramatic change of the crystallite sizes to $65.13 \mathrm{~nm}$, which is due to the presence of oxide 
compounds in the structure. Large amount of oxygen (around 40\%) in the structure leads to appearance of local degradation zones, which are determined by susceptibility to easily dissolution in alkalies and acids media. In addition, fast uncontrolled deposition process at potential of $2.0 \mathrm{~V}$ leads to walls thinning.

Table 2. Lattice parameters and the average crystallite size of Zn-based nanotubes formed at different potentials.

\begin{tabular}{ccc}
\hline $\begin{array}{c}\text { Deposition potential, } \\
\mathrm{V}\end{array}$ & $\begin{array}{c}\text { Lattice parameters, } \\
\AA\end{array}$ & $\begin{array}{c}\text { The average } \\
\text { crystallites size, } \mathrm{nm}\end{array}$ \\
\hline \multirow{2}{*}{1.25} & $\mathrm{a}=(2.6650 \pm 0.0008)$ & \\
& $\mathrm{c}=(4.9273 \pm 0.0050)$ & \\
1.50 & $\mathrm{a}=(2.6648 \pm 0.0009)$ & \\
& $\mathrm{c}=(4.9289 \pm 0.0053)$ & \\
1.75 & $\mathrm{a}=(2.6655 \pm 0.0006)$ & $16.3 \pm 1.5$ \\
& $\mathrm{c}=(4.9231 \pm 0.0045)$ & \\
2.00 & $\mathrm{a}=(2.6837 \pm 0.0011)$ & \\
& $\mathrm{c}=(4.9567 \pm 0.0011)$ & \\
\hline
\end{tabular}

\section{Conclusions}

Zn-based nanotubes have been produced by template synthesis method via electrochemical deposition in pores of PET templates. The morphology and structure investigations performed by scanning electron microscopy, energy dispersive spectroscopy, X-ray diffraction analysis have shown, that synthesized nanotubes have diameter of $400 \pm 10 \mathrm{~nm}$ and length of $11.5 \pm 0.5 \mu \mathrm{m}$. As a result of studies of deposition potential influence on structural properties of $\mathrm{Zn}$-based nanotubes were established. At deposition potentials 1.25 and $1.5 \mathrm{~V}$ surfaces of nanotubes have impurities and formation of the $\mathrm{ZnO}$ phase is determined. At deposition potential of $1.75 \mathrm{~V}$ nanotubes consist of pure $\mathrm{Zn}$ without impurities and oxides. The increase of deposition potential up to $2.0 \mathrm{~V}$ provides fast uncontrolled deposition process and formation of highly oxidized hollow structure of nanotubes with fragile walls. Moreover, the increase of deposition potential leads to walls thinning. We have shown, low cost and scalable template synthesis method allows production $\mathrm{Zn}$ and $\mathrm{ZiO}$ nanotubes with controlling shape and size, which are prospective for using as catalysts or components of flexible electronic elements.

\section{Acknowledgements}

The authors acknowledge the support of the work in frames of H2020 - MSCA - RISE2017 778308 - SPINMULTIFILM Project

\section{References}

[1] V. Vega, T. Böhnert, S. Martens, M. Waleczek, J.M. Montero-Moreno, D. Görlitz, V.M. Prida and K. Nielsch. Nanotechnology. 23(46) (2012) 465709.

[2] M.A. Kashi, A. Ramazani, S. Doudafkan and A.S. Esmaeily. Appl Phys A Mater Sci Process. 102(3) (2011) 761-764.

[3] R.P. Chauhan and P. Rana. Radiat Meas. 83 (2015) 43-46. 
[4] A.L. Kozlovskiy, I. V Korolkov, G. Kalkabay, M.A. Ibragimova, A.D. Ibrayeva, M. V Zdorovets, V.S. Mikulich, D. V Yakimchuk, A.E. Shumskaya and E.Y. Kaniukov. J Nanomater. 2017 (2017) 1-10.

[5] I. V. Korolkov, D.B. Borgekov, A.A. Mashentseva, O. Güven, A.B. Atıc1, A.L. Kozlovskiy and M. V. Zdorovets. Chem Pap. June 2017 (2017)

[6] M.V. Zdorovets and A.L. Kozlovskiy. J Mater Sci Mater Electron. 0(0) (2017) 0.

[7] A. Kozlovskiy, M. Zdorovets, E. Kanukov, E. Shumskaya, K. Kadyrzhanov and V. Rusakov. Chem Bull Kazakh Natl Univ. (2) (2016) 4-11.

[8] S.E. Demyanov, E.Y. Kaniukov, a. V. Petrov and E.K. Belonogov. Bull Russ Acad Sci Phys. 72(9) (2008) 1193-1195.

[9] E. Kaniukov, D. Yakimchuk, G. Arzumanyan, H. Terryn, K. Baert, A. Kozlovskiy, M. Zdorovets, E. Belonogov and S. Demyanov. Philos Mag. 6435 (2017) 1-16.

[10] S. Demyanov, E. Kaniukov, A. Petrov and V. Sivakov. Sensors Actuators A Phys. 216 (2014) 64-68.

[11] a. V. Trukhanov, S.S. Grabchikov, a. N. Vasiliev, S. a. Sharko, N.I. Mukhurov and I. V. Gasenkova. Crystallogr Reports. 59(5) (2014) 744-748.

[12] S.S. Grabchikov, A.V. Trukhanov, S.V. Trukhanov, I.S. Kazakevich, A.A. Solobay, V.T. Erofeenko, N.A. Vasilenkov, O.S. Volkova and A. Shakin. J Magn Magn Mater. 398 (2016) 49-53.

[13] V.A. Ketsko, E.N. Beresnev, M.A. Kop'eva, L. V. Elesina, A.I. Baranchikov, A.I. Stognii, A. V. Trukhanov and N.T. Kuznetsov. Russ J Inorg Chem. 55(3) (2010) 427-429.

[14] A.V. Trukhanov, S.S. Grabchikov, A.A. Solobai, D.I. Tishkevich, S.V. Trukhanov and E.L. Trukhanova. J Magn Magn Mater. 443 (2017) 142-148.

[15] D.I. Tishkevich, S.S. Grabchikov, L.S. Tsybulskaya, V.S. Shendyukov, S.S. Perevoznikov, S.V. Trukhanov, E.L. Trukhanova, A.V. Trukhanov and D.A. Vinnik. J Alloys Compd. 735 (2018) 1943-1948.

[16] G. Jiangfeng, D. Zhaoming, D. Qingping, X. Yuan and Z. Weihua. J Nanomater. 2010 (2010) 1-6.

[17] L. Li, S. Pan, X. Dou, Y. Zhu, X. Huang and Y. Yang. Society. 2007 (2007) 7288-7291.

[18] F.L. Boughey, T. Davies, A. Datta, R.A. Whiter, S.L. Sahonta and S. Kar-Narayan. Nanotechnology. 27(28) (2016)

[19] J. De Meutter, J. Vandenameele, A. Matagne and E. Goormaghtigh. Analyst. 142(8) (2017) 1371-1380.

[20] A.L. Kozlovskiy, D.I. Shlimas, M. V Zdorovets and K.K. Kadyrzhanov. Chem Bull Kazakh Natl Univ. 4(80) (2015) 40-48.

[21] E.Y. Kaniukov, E.E. Shumskaya, D. V. Yakimchuk, A.L. Kozlovskiy, M.A. Ibragimova and M. V. Zdorovets. J Contemp Phys (Armenian Acad Sci. 52(2) (2017) 155-160.

[22] I. V Korolkov, A.A. Mashentseva, O. Güven, M. V Zdorovets and A.A. Taltenov. Nucl INSTRUMENTS METHODS Phys. 2015 (2015)

[23] I. V. Korolkov, D.B. Borgekov, A.A. Mashentseva, O. Güven, A.B. Atıcı, A.L. Kozlovskiy and M. V. Zdorovets. Chem Pap. 71(12) (2017) 2353-2358.

[24] A.L. Kozlovskiy, D.I. Shlimas, A.E. Shumskaya, E.Y. Kaniukov, M. V. Zdorovets and K.K. Kadyrzhanov. Phys Met Metallogr. 118(2) (2017) 164-169. 